\title{
Competências, Gestão de Competências e Profissões: Perspectivas de Pesquisas
}

\section{Competencies, Management of Competencies and Professions: Perspectives of Research}

\begin{abstract}
Kely César Martins de Paiva* Doutora em Administração pelo CEPEAD/FACE/UFMG. Membro do Núcleo de Relações de Trabalho e Tecnologias de Gestão - NURTEG (Faculdade Novos Horizontes), Belo Horizonte/MG, Brasil.

Marlene Catarina de Oliveira Lopes Melo Doutora pela Université de Paris IX, Dauphine, França. Diretora Acadêmica da Faculdade Novos Horizontes, Belo Horizonte/MG, Brasil.
\end{abstract}

*Endereço: Faculdade Novos Horizontes e Universidade FUMEC, Rua Alvarenga Peixoto, 1270, Bairro Santo Agostinho, Belo Horizonte/MG, 30180-120. E-mail: serra.bh@terra.com.br/serra.bh@gmail.com 


\title{
Resumo
}

Os objetivos deste ensaio foram refletir sobre os conceitos de competência profissional, gestão de competências e profissão, e indicar possibilidades de pesquisas. Após a reflexão, procedeu-se à reconceituação de competência profissional e de profissão, considerandose aspectos que implicam uma diversidade complexa e de difícil gerenciamento em múltiplas esferas e, inevitavelmente, um redimensionamento dos processos de profissionalização de determinadas ocupações. Para pesquisas, propôs-se uma agenda que contempla aspectos metodológicos (abordagens qualitativas para dar profundidade à compreensão dos temas e das suas inter-relações, e abordagens quantitativas com vistas à extensão de conclusões e validação de modelos) e temáticos (um leque de opções contemplando profissões que se encontram em momentos diferenciados no que diz respeito ao processo de profissionalização, buscando compreender aspectos particulares e extensivos a outras demais). O cumprimento de tal agenda visa colaborar, tanto conceitual e academicamente, no sentido de precisar e expandir a delimitação dos construtos abordados, como prática e profissionalmente, para fornecer subsídios para um trânsito efetivo dos atores sociais envolvidos nos processos de profissionalização a que se tem assistido e presenciado.

Palavras-chave: competência; gestão de competências; profissão; profissionalismo.

\begin{abstract}
The objectives of this assay had been to reflect on the concepts of professional competence, management of competences and profession, and to indicate possibilities of research. After the reflection, a re-conceptualization of professional competence and profession was done, considering aspects that imply in a complex diversity that is difficult to manage in multiple spheres and, inevitably, in a redesign of the professionalization processes of determined occupations. For research, it proposes an agenda that contemplates methodology (qualitative boardings to give depth to the understanding of the subjects and their relations, and quantitative boardings that aim the extension of conclusions and validation of models) and thematic aspects (a fan of options contemplating professions that are at differentiated moments in terms of the professionalization process, searching to understand particular and extensive aspects to others groups). The fulfilment of the related agenda aims at to collaborate in two ways: conceptual and academic, in the direction to exact and to expand the delimitation of the boarded constructs; and practical and professional, to give subsidies for an effective transit of the involved social actors in the professionalization processes that we have attended and witnessed.
\end{abstract}

Key words: competency; management of competencies; profession; professionalism. 


\section{INTRODUÇÃO}

Há quase dois séculos atrás, Aléxis de Tocqueville realizou uma pesquisa longitudinal em que analisou o fenômeno das profissões liberais, ou livres, atentando para disparidades em termos de remuneração. Esse estudo contemplou funcionários públicos e mensageiros de escritório, comparando Estados Unidos da América e França. Tocqueville associou as diferenças encontradas aos variados níveis de democracia em períodos de tempo e países distintos, ou seja, mais democracia nos EUA que na França e mais democracia na França em 1833 que em 1810, redundando em maiores salários e status para diferentes categorias profissionais. Para ele, as questões políticas ditavam as normas salariais, pois a aristocracia nas referidas épocas tendia a privilegiar postos de trabalho que ela própria, ou seus familiares, poderiam ocupar, no caso os funcionários públicos (Scitovisky, 1966).

Scitovisky (1966), por sua vez, debruçou-se sobre alguns países ocidentais (Canadá, Dinamarca, França, Alemanha, Noruega, Suécia, Reino Unido e Estados Unidos), em período que abrange praticamente a primeira metade do século XX, abraçando os seguintes profissionais: advogados, médicos, dentistas, funcionários públicos e professores universitários. Dois pontos foram alvo de análise para o autor: a relação entre crescimento econômico e avanço da democracia, e a perda de status econômico das classes profissionais e intelectuais. Segundo ele, aos fatores econômicos referenciados por Tocqueville, somam-se outros, sendo digno de destaque o aumento da disponibilidade de educação em nível superior e, daí, a diminuição do custo individual de formação. Aumentando-se a oferta de profissionais, seus rendimentos caíram. Do lado da demanda, a produtividade correlata era de difícil mensuração, implicando empecilhos quanto à sua conexão direta com a remuneração. Apesar das limitações de um estudo comparativo da monta do realizado por Scitovisky (1966), como as diferenças de poder aquisitivo entre países / anos dos valores em estudo, processos inflacionários, utilização de dados secundários de fontes distintas etc., o autor questiona a manutenção do status profissional em determinadas espaciotemporalidades, e as formas e os recursos que os profissionais utilizam nesse trajeto, como associações coletivas, pressões institucionais etc.

No Brasil, a contribuição de Coelho (1999) é instigante, pois retrata a evolução profissional, e os meandros desse percurso, em medicina, engenharia e advocacia no Rio de Janeiro, no período de 1822 a 1930 . O autor destacou as influências do Estado, das associações coletivas, incluindo sindicatos, das instituições de ensino 
e dos próprios profissionais, na pessoa dos representantes das elites. Ele realçou o aspecto processual da profissionalização, isto é, como uma profissão pode ter seu status elevado ou diminuído na sociedade, em virtude das mudanças extra, inter e intra-profissionais.

Sob ótica semelhante, Carvalho e Azevedo (2004) assinalam uma mudança de status nas profissões liberais, na promulgação da Consolidação das Leis do Trabalho [CLT], em 1943, em virtude da institucionalização dos sindicatos como representantes de segmentos de trabalhadores, responsáveis por contratos coletivos, dissídios, acordos etc. Em 1953 foi criada a Confederação Nacional das Profissões Liberais [CNPL], entidade multiprofissional que abriga 28 das 34 federações nacionais, estaduais ou interestaduais. A importância desses profissionais no atual contexto nacional pode ser ilustrada de várias formas. Segundo dados do Tribunal Superior Eleitoral [TSE], cerca de 5\% dos eleitores caracterizam-se como profissionais liberais e de nível superior. Nas eleições municipais de 2000, quase $9 \%$ dos prefeitos e vereadores eleitos pertenciam a tais categorias profissionais; já nas eleições gerais de 2002, eles somaram em torno de $30 \%$ dos eleitos, com destaque para advogados, médicos e engenheiros. Outro exemplo salientado por Carvalho e Azevedo (2004) é a participação de $10 \%$ dos profissionais liberais na arrecadação anual total do imposto sindical. Em tal reflexão, os autores atentam para a necessidade de um esforço conjunto no processo de profissionalização, que contemple sociedades científicas, acadêmicas e de pesquisa, e também conselhos profissionais, reguladores e fiscalizadores das profissões.

Assim, a ênfase dada por Coelho (1999) e Carvalho e Azevedo (2004) sobre os domínios sociais, políticos, econômicos e técnicos que envolvem uma profissão está diretamente conectada à construção de um sistema profissional pautado em competências, conforme disserta Ramos (2001). Para esta autora, no bojo desse sistema estariam estrategicamente conciliados projetos individuais, institucionais e sociais. Segundo ela

O projeto individual implica a responsabilidade que tem o indivíduo na gestão de sua própria carreira profissional. O projeto das empresas, seja qual for o tipo, deve cuidar das relações de competitividade nas organizações e de suas responsabilidades em desenvolver as competências individuais. Por fim, o projeto social tem como foco a dimensão coletiva do profissionalismo e o papel assumido pelo governo e pela sociedade em geral (organizações sociais e profissionais) em prover os recursos e oportunidades iguais às pessoas para se tornarem profissionais e terem seu profissionalismo reconhecido. Os sistemas de competência profissional têm-se apresentado como tentativa de realizar essa conciliação (Ramos, 2001, p. 73). 
Dessa maneira, a competência profissional e sua gestão não aparecem descoladas da realidade prática; pelo contrário, como conhecimento manifesto em ações, comportamentos, potenciais e, fundamentalmente, resultados, a competência assume valor diferenciado e reconhecido no mercado. Esse fato toma vulto ainda maior, quando se pensa em torno de profissões, como ocupações que passaram por um processo que, conforme Elias (1987), Boudon e Bourricaud (1993), Waddington (1996), A. G. Johnson (1997) e Roos (2000), dentre outros autores, contempla os seguintes aspectos: especialização acadêmica, ou seja, incluem saber especializado, validado por instituições de ensino, normalmente de ensino superior, e reconhecido socialmente; auto-regulação coletiva entre os próprios membros e via instrumentos legais; e autonomia, altruísmo e independência na execução de suas atividades provenientes da especialização e de uma relação singular com o cliente.

Uma profissão pode ser compreendida, portanto, como estágio avançado, diferenciado ou refinado de ocupação, cujos praticantes conseguem certo grau de monopólio em relação aos demais indivíduos na sociedade em determinada espaciotemporalidade. $\mathrm{O}$ processo de profissionalização, isto é, de trânsito de status entre ocupação e profissão, como salienta Coelho (1999), envolve diferentes atores sociais: instituições de ensino, o Estado, seus próprios praticantes e a sociedade. Nesse sentido, Veiga (1998) afirma que o processo de profissionalização não é movimento linear e hierárquico, não se tratando de questão meramente técnica, implicando a relação entre profissionalismo e gestão de competência.

Sendo assim, descortinam-se possibilidades de pesquisa sobre a figura ${ }^{(1)}$ dos profissionais liberais, tendo em vista as perspectivas que se abrem e as exigências que se impõem a cada profissão, as quais se realizam num ambiente ao mesmo tempo amplo - no contexto organizacional, pautado em determinações legais e vinculado a instituições de interesse coletivo - e específico - no âmbito da formação e do desenvolvimento de competências, formais e informais, e do próprio profissional, enquanto sujeito de sua história.

Os objetivos deste ensaio, portanto, são dois: primeiro, refletir sobre os conceitos de competência profissional, gestão de competências e profissão; e, segundo, indicar possibilidades de pesquisas, tanto em termos metodológicos como temáticos. Note-se que a terminologia 'gestão de competências' será utilizada de maneira a sintetizar tanto os esforços organizacionais, mais conhecidos como 'gestão por competências', como os individuais, coletivos e sociais. Evitar-se-á a terminologia 'profissão liberal' e 'profissão livre', em virtude de o adjetivo referirse a características que não se mostram compatíveis com a sociedade contemporânea, principalmente devido aos impactos antimonopólio e antiexclusividade que têm atingido as profissões liberais clássicas, como apontam 
Villa (1998) e Carvalho e Azevedo (2004). Conforme transcrevem estes últimos, os estatutos da CNPL definem o profissional liberal como "aquele legalmente habilitado à prestação de serviços de natureza técnico-científica de cunho profissional, com a liberdade de execução que lhe é assegurada pelos princípios normativos de sua profissão, independentemente de vínculo da prestação de serviço" (Carvalho \& Azevedo, 2004, p. 15), definição esta que mais se alinha ao conceito proposto neste artigo.

Convém ressaltar que os estudos sobre profissões são escassos no país (Barbosa, 2003; Bonelli \& Donatoni, 1996), assim como as pesquisas sobre competências e gestão de competências, temas que começam a ser discutidos em maior profundidade na Administração, a partir do final da década de 90 (Bitencourt \& Barbosa, 2004). Por outro lado, a aproximação de abordagens / paradigmas distintos (profissões / institucionalismo; competências / fenomenologia) pode trazer, além dos riscos ${ }^{(2)}$, ganhos interessantes para ambos, para o desenvolvimento de outras teorias e, sobretudo, para uma melhor compreensão dos fenômenos, conforme sublinham Lewis e Grimes (2005).

\section{Referências Conceituais}

\section{Competência Profissional}

A noção de competência vem do latim competentia, derivada de competere, "chegar ao mesmo ponto", oriunda de petere, "dirigir-se para". Refere-se a "o que convém"; no francês antigo, significava "apropriado" (Dadoy, 2004, p. 108).

O conceito de competência, segundo Le Boterf (2003), é conceito em construção. Torna-se necessário, portanto, elencar alguns autores que já se debruçaram sobre o tema para, ao final, traçar o conceito a ser utilizado para fins dessa reflexão.

Dutra, Hipólito e Silva (1998) sublinham que, para um grupo de autores ${ }^{(3)}$ que realizaram seus trabalhos nas décadas de 70 e 80, na maioria americanos, competência significa o conjunto de qualificações que um indivíduo detém para executar trabalho com nível superior de desempenho. Segundo Dutra et al. (1998), após a década de 80 , outros autores ${ }^{(4)}$, predominantemente europeus, contestaram esse conceito de competência, associando-o às realizações das pessoas, àquilo que elas provêem, produzem, entregam. Este segundo grupo percebe que o fato de uma pessoa possuir as qualificações necessárias para determinado trabalho não garante que elas sejam realmente utilizadas e, conseqüentemente, que se realize tal atividade produtiva. 
McLagan (1997) tenta resumir esta questão, afirmando que, no mundo do trabalho, a palavra competência tem assumido diversos significados normalmente alinhados a características dos indivíduos ou das suas atividades produtivas e resultados decorrentes. Numa perspectiva semelhante, Woodruffe (1991) diferencia, na língua inglesa, competency de competence. Segundo este autor, a primeira refere-se a dimensões de comportamento por trás do desempenho percebido como competente, enquanto a segunda designa áreas de trabalho em que a pessoa é vista como competente. Competency, nessa perspectiva, relacionase a características do indivíduo e competence, por sua vez, diz respeito ao desempenho no cargo e aos resultados alcançados, aproximando-se do conceito de qualificação do Centro Interamericano de Investigação e Documentação sobre Formação Profissional [CINTERFOR] da Organização Internacional do Trabalho [OIT] - muito difundido na América Latina, conforme salienta Ramos (2001). Para o CINTERFOR, o conceito de qualificação incorpora um conjunto de conhecimentos e habilidades adquiridos pelas pessoas no decorrer dos processos de socialização e de educação / formação, que as capacitavam potencialmente a desempenhar tarefas num posto de trabalho de maneira satisfatória (CINTERFOR - Projeto 128, citado em Brígido, 1999). Já o conceito de competência diz respeito à capacidade real para atingir um fim em determinado contexto, capacidade esta constituída por certos conhecimentos e habilidades necessários do indivíduo (idem).

Conforme ressaltam Brígido (1999) e Ramos (2001), qualificação refere-se à organização, ao posto de trabalho ou cargo, à potencialidade de ação, à possibilidade / facilidade de transferência, a algo estático e absoluto no tempo e no espaço; já competência relaciona-se à profissão (ou ocupação), ao indivíduo, aos resultados reais por ele obtidos, à dificuldade / impossibilidade de transferência, a algo dinâmico, processual, relativo: enfim, a competência é uma 'construção social' (Tomasi, 2004a, p. 153).

Ainda sobre a diferenciação qualificação-competência, as contribuições presentes em Tomasi (2004b) são dignas de realce. Dugué (2004) explicita os ataques frontais sofridos pelo conceito de qualificação, principalmente no final da década de 70 e emersão do conceito de competência, como resposta às novas demandas do mercado e da sociedade. Roche (2004) lembra a descrição de Demailly (1987) acerca da competência como algo a mais, que torna eficiente a qualificação; a autora realizou, ainda, uma comparação entre o conceito de competência e três dimensões da qualificação - social, experimental e conceitual -, mostrando pontos de interseção e de dispersão entre eles.

Focando na conceituação de competência, Le Boterf (2003) a define como a prática do que se sabe em certo contexto, geralmente marcado pelas relações de trabalho, pela cultura organizacional, pelas contingências, por diversas limitações 
etc. Para ele, competência se traduz em ação, em saber ser e, daí, a mobilizar conhecimentos em diferentes situações.

Outros autores que trabalham sobre o construto, como Ropé e Tanguy (1997), Dutra et al. (1998) e Fleury e Fleury (2001), pensam em competência como sendo o resultado da soma das duas linhas apresentadas anteriormente. Dessa forma, eles alargam o conceito, evidenciando não apenas a presença de um conjunto de qualificações, como a necessidade da sua manifestação prática em determinado contexto. Assim, o conceito amplia sua abrangência na medida em que engloba a geração de resultados afinados aos objetivos organizacionais.

Dessa maneira, o conceito de competência vai além da simples qualificação. Zarifian (2001) afirma que ele se relaciona com capacidade do indivíduo de assumir iniciativas, estar além do prescrito, compreender e dominar situações em constante mutação, ser responsável e reconhecido por outros. A percepção desse autor deriva de basicamente três pontos: a natureza contingencial do mundo moderno, o teor participativo da comunicação intra-organizacional e seus impactos na visão de serviços dentro e fora das organizações. Le Boterf (2003) acrescenta ao construto variáveis relacionadas à aprendizagem, na medida em que situa a competência num ponto convergente entre a pessoa, sua formação educacional e sua experiência profissional. Esse autor afirma, ainda, que competência é um saber agir responsável que engloba saber mobilizar, integrar e transmitir conhecimentos, recursos e habilidades, em determinado contexto profissional. Assim sendo, tal saber gera uma conseqüência inevitável, que é seu reconhecimento por outros.

Na mesma linha, Sparrow e Bognanno (1994) correlacionam o conceito a um leque de atitudes que permitam adaptação rápida a um ambiente cada vez menos estável, incitem o uso produtivo do conhecimento, e promovam inovação e aprendizagem permanentes. Tais atitudes configuram-se como relevantes para obtenção de alto desempenho no exercício de funções, ao longo de uma carreira profissional e no contexto de uma estratégia corporativa. Ruas (2001, 2005) compartilha dessas perspectivas em suas pesquisas e, a exemplo de Le Boterf (2003), reúne os aspectos discutidos em três grandes eixos percebidos como clássicos: o conhecimento - saber, as habilidades - o saber fazer, e as atitudes o saber ser / agir. Já Perrenoud (1999) recorre ao conceito de 'esquema' para definir competência. Para ele, os esquemas permitem a mobilização de conhecimentos, métodos, informações e regras para enfrentar uma situação que exige uma série de operações mentais de alto nível. Nas palavras do autor:

Uma competência seria, então, um simples esquema? Eu diria que antes ela orquestra um conjunto de esquemas. Um esquema é uma totalidade constituída, que sustenta uma ação ou operação única, enquanto uma competência com 
uma certa complexidade envolve diversos esquemas de percepção, pensamento, avaliação e ação, que suportam inferências, antecipações, transposições analógicas, generalizações, apreciação de probabilidades, estabelecimento de um diagnóstico a partir de um conjunto de índices, busca das informações pertinentes, formação de uma decisão etc. (Perrenoud, 1999, p. 24).

Indo além dos conhecimentos, a conceituação de competência de Perrenoud (1999) espelha dificuldades em termos da sua gestão nas organizações, pois o esquema pode conter alguma rigidez, mas sua orquestração não, em virtude de seu caráter contingencial. Nessa ótica, o conceito de competência se aproxima do de "habitus" de Bourdieu (2003), ou seja, um conjunto de esquemas que permitem gerar uma infinidade de práticas ao mesmo tempo adaptadas a situações, renováveis, mas não explícitas. Assim, "toda competência está, fundamentalmente, ligada a uma prática social de certa complexidade" e todas as práticas, incluindo as profissionais, "admitem uma forma profissional", o que é "perfeitamente normal, pois toda competência amplamente reconhecida evoca uma prática profissional instituída, emergente ou virtual" (Perrenoud, 1999, pp. 35-36).

Por sua vez, Fleury e Fleury (2001, p. 21) propõem um conceito, segundo eles ao mesmo tempo abrangente e preciso, em que competência é definida como "um saber agir responsável e reconhecido, que implica mobilizar, integrar, transferir conhecimentos, recursos, habilidades, que agreguem valor econômico à organização, e valor social ao indivíduo". Nessa abordagem, a competência profissional seria composta por sete saberes: saber agir, saber mobilizar, saber compreender, saber aprender, saber comprometer-se, saber assumir responsabilidades e ter visão estratégica. O impacto de agregar valor é, na visão desses autores, elemento de ligação entre indivíduo e organização: para o primeiro agrega-se valor social e, para a segunda, valor econômico. Desenha-se, portanto, a relação entre o contexto, o processo de aprendizagem e a geração e manutenção de competências. Tal relação está em congruência com a corrente teórico-filosófica construtivista, de origem francesa, que percebe o processo de aprendizagem como mecanismo de desenvolvimento das competências profissionais. $\mathrm{Na}$ visão de Desaulniers (1997), como o agir competente resulta de empreendimentos originários de variadas fontes (indivíduo, escola, Estado, sociedade), ele gera ganhos para todos, constituindo-se em uma estratégia que se presta ao desenvolvimento e à consolidação da cidadania.

Por outro lado, cabe frisar que os conceitos de competência profissional, até então alinhados neste artigo, parecem não contemplar os aspectos políticos e ideológicos que permeiam o construto 'competência', indicados por Ramos (2001), os quais legitimam diferenças intra-organizacionais e intraprofissionais, assim como individualizam uma construção que é, de fato, coletiva. Sobre o 
dueto qualificação-competência, a autora ressalta a individualização do segundo conceito, fato que, segundo ela, gera consequiências (danosas) à coletividade pertinente.

Cabe, portanto, uma visão mais ampla da conceituação de competência profissional, como a desenvolvida por Cheetham e Chivers (1996, 1998, 2000). Em seu modelo teórico, estes autores buscam integrar várias abordagens, que privilegiam conhecimento tácito e sua aplicação, conhecimento acadêmicoprofissional, padrões profissionais, atributos pessoais, controle, desenvolvimento e mediação de outras competências. Segundo eles, tal modelo considera aspectos processuais e dinâmicos, assim como individuais, coletivos e sociais, além de atentar para macrorresultados (da atividade profissional), microrresultados (de atividades específicas) e resultados parciais (de uma atividade específica). O núcleo do modelo é constituído por quatro competências centrais (cognitiva, funcional, comportamental ou pessoal, ética) compostas por grupos de habilidades. Sobre essas competências estariam as metacompetências e, permeando todas elas, as transcompetências, que poderiam ser assim exemplificadas: comunicação, criatividade, solução de problemas, aprendizagem e autodesenvolvimento, agilidade mental, análise e reflexão. Como resultados da competência profissional, Cheetham e Chivers (1998) alinham os percebidos pelo próprio sujeito e pelos outros, a que ele tem acesso através dos mecanismos de feedback. Tais percepções dos resultados (em termos macro, micro e parciais) levariam o profissional à reflexão sobre a ação e também na ação ${ }^{(5)}$, daí sua inclusão nas metacompetências ${ }^{(6)}$. Em função disso, surgiu a necessidade de considerar no modelo as variáveis personalidade e motivação, já que ambas influenciam decisões pessoais acerca das necessidades e das possibilidades reais e potencias de se fazer coisas. Por fim, os autores reconhecem a importância do contexto de trabalho e do ambiente de trabalho para a competência profissional: contexto como "a situação particular na qual um profissional é requisitado a operar" e ambiente como "as condições físicas, culturais e sociais que envolvem um indivíduo no trabalho" (Cheetham \& Chivers, 1998, p. 273).

Após apresentarem e discutirem os resultados de suas pesquisas, Cheetham e Chivers (2000, p. 374) frisaram que a adoção de seu modelo permitiu examinar

a natureza da prática profissional (como os profissionais operam), a natureza das modernas profissões, competência profissional, como pessoas reconhecem competências profissionais em outras e como pessoas adquirem sua competência profissional (um exame da contribuição de ambos o desenvolvimento formal e outros tipos de experiência formativa). 
Assim, esse modelo conceitual foi considerado metodologicamente útil para fins das pesquisas propostas neste artigo, sendo necessário acrescentar outras variáveis com vistas a redimensioná-lo para o contexto das profissões.

Com o mesmo intuito, propõe-se o seguinte conceito de competência profissional: mobilização de forma particular pelo profissional na sua ação produtiva de um conjunto de saberes de naturezas diferenciadas (que formam as competências intelectual, técnico-funcionais, comportamentais, éticas e políticas) de maneira a gerar resultados reconhecidos individual (pessoal), coletiva (profissional), econômica (organização) e socialmente (sociedade). Concebe-se, então, competência profissional como a meta-reunião de maneira singular e produtiva de competências compostas por saberes variados. Acrescentou-se a 'competência política', com vistas a considerar as relações de poder inerentes a qualquer estrutura organizacional e, daí, as razões e formas de atuação do profissional na teia política intra e interorganizacional.

Resgatando a percepção do caráter social da construção e da manutenção da competência profissional, conforme sublinha Dubar (1997), nega-se uma formação pontual, estática ou descolada da realidade prática e da reflexão conceitual. Neste ponto, torna-se necessário conceituar e discutir alguns aspectos relevantes pertinentes à gestão de competências.

\section{Gestão de Competências}

Zarifian (2001, p. 126) afirma que "a lógica da competência leva a revisitar o conjunto de práticas de gestão de recursos humanos", abraçando os processos de recrutamento, de mudança da organização do trabalho, de avaliação, de identificação de potenciais e de construção de projetos individuais, assim como as políticas de formação e de carreira. Segundo este autor, cabe à gestão de recursos humanos dar coerência global ao conjunto de ações e, dessa maneira, conciliar os interesses da organização e os das pessoas.

Para Brandão e Guimarães (2001), a gestão de competências faz parte de um sistema maior de gestão organizacional: a partir da estratégia organizacional, ela "direciona suas ações de recrutamento e seleção, treinamento, gestão de carreira e formalização de alianças estratégicas, entre outras, para a captação e o desenvolvimento das competências necessárias para atingir seus objetivos" (Brandão \& Guimarães, 2001, p. 11), caracterizando um processo circular e de multinível que engloba toda a organização. Convém lembrar que, na visão desses autores, o processo de gestão de competências se constitui em "mecanismos de controle social de trabalhadores e de manutenção das estruturas de poder das organizações" (Brandão \& Guimarães, 2001, p. 13). 
Dutra (2004) compartilha da visão anterior e disserta sobre o conceito de competência, considerando fases de sua utilização: como central na definição das políticas de seleção e desenvolvimento de pessoas; sobre a diferenciação por níveis de complexidade; como conceito integrador da gestão de pessoas e destas com os objetivos estratégicos da organização; e da apropriação por parte das pessoas dos conceitos de competência. Segundo esse autor, um dos maiores desafios relacionados à gestão de competências é a identificação precisa das competências demandadas pela empresa e pela sociedade, de maneira a garantir vantagens competitivas ${ }^{(7)}$ e dar foco nos processos educativos. Por outro lado, o autor recomenda que alguns 'efeitos perversos' sejam evitados, a saber: a desarticulação conceitual em relação à prática, a exploração do trabalhador, o descolamento estratégico do modelo adotado, e a desarticulação com as pessoas.

Já Ramos (2001) define a gestão por competências como organizada a partir dos seguintes eixos: gestão previsional de empregos e competências, a partir da individualização dos trabalhadores no que diz respeito às suas perspectivas $\mathrm{e}$ possibilidades de mobilidade horizontal e / ou transversal; desenvolvimento de competências individuais, diretamente relacionado com mudanças nas políticas organizacionais de formação de pessoal; reconhecimento das competências do trabalhador, desconsiderando-se suas origens e formas, e incentivando suas próprias ações a esse respeito; e, estabelecimento de políticas avaliativas e remuneratórias por competências. Ramos (2001) salienta as mudanças nas relações de trabalho e nas relações educativas, tendo em vista a inserção do conceito de competências nas políticas e práticas de gestão. A autora frisa o enfraquecimento do poder de barganha tanto individual como coletivo, fruto das ações institucionais individualizantes legitimadas sob a égide da gestão de competências, conforme também atenta Manfredi (1999). Na França, Pages, Bonetti, Gaulesiac e Descendre (1987) apontaram em direção semelhante, chamando atenção para o fato, relativamente à inserção de 'novas' tecnologias de gestão em organizações, no mesmo sentido concluindo Lima (1995) e Melo (1991) em suas pesquisas no Brasil.

Por outro lado, Bitencourt e Barbosa (2004) chamam a atenção para dificuldades operacionais da gestão de competências, principalmente no que se refere às estruturas remuneratórias e às políticas particularistas das empresas, sem se omitirem na ênfase em resultados organizacionais, a despeito das expectativas de recompensas individuais. Tais dificuldades são, também, apontadas por Dutra (2004).

Por fim, percebeu-se ao analisar bibliografias pertinentes que muitos autores ${ }^{(8)}$, ao se referirem à gestão de (ou por) competências, retomavam a conceituação 
do construto 'competência', deixando lacunas sobre políticas e procedimentos efetivos, em termos das atividades particulares da gestão de pessoas. Tais atividades podem ser assim exemplificadas: descrição, análise e avaliação dos cargos; delineamento de carreiras; recrutamento e seleção; admissão e demissão; treinamento e desenvolvimento; avaliação funcional (desempenho, resultados e potencial); saúde e segurança ocupacional; relações com entidades de classe / sindicatos etc. Como essas atividades são conjugadas sob a égide da competência profissional nessas bibliografias, mais se assemelham à concepção de 'qualificação' do que efetivamente competência. Gerir o intangível, abraçando a personalidade e a motivação dos profissionais, ainda se apresenta como questão na Administração, para a qual Dugué (2004) apresenta algumas pistas conceituais no que se refere ao âmbito da empresa (seu caráter multifacetado: integrador no sistema hierárquico, orientador em termos de mobilidade, seletivo no sistema de reconhecimento) e ao âmbito social (planificação de mercado e integração entre trabalho e formação). Já Heijden e Barbier (2004) são mais pragmáticas: o gerenciamento de competências deve preconizar seu desenvolvimento e a flexibilidade dos empregados, a partir de iniciativas que partam, ao mesmo tempo, tanto do gerenciamento como do empregado.

Reforça-se, assim, a necessidade de construção de um sistema profissional pautado em competências que concilie, de maneira estratégica, projetos individuais, institucionais e sociais, conforme a descrição de Ramos (2001), citada anteriormente. A conexão entre profissionais, organizações, educação e governo implicaria, inevitavelmente, certo redimensionamento do processo de profissionalização relacionado, nos moldes discutidos pela Sociologia das Profissões, conforme se segue.

\section{Profissão}

Profession é uma palavra da linguagem comum que entrou de contrabando na linguagem científica; mas é, sobretudo, uma construção social, produto de todo um trabalho social de construção de um grupo e de uma representação dos grupos, que se insinuou docemente no mundo social (Bourdieu, 2003, p. 40).

De acordo com Gyarmati (1975), as profissões se distinguem das ocupações basicamente em virtude da propriedade da autonomia, enquanto direito de regular e controlar sua própria atividade, e do monopólio profissional, fruto de leis que impedem indivíduos formalmente não considerados membros de determinado grupo profissional de competir com seus profissionais. A autonomia profissional é, segundo o autor, uma característica ambígua, porquanto, por um lado, permite às profissões se livrarem do controle da sociedade à qual deveriam, em princípio, servir; por outro lado, a imagem da profissão diz de um poder cuja utilidade visa exclusiva e permanentemente ao benefício da sociedade. O autor percebe as 
profissões como os mais importantes grupos de poder nas sociedades industrializadas.

De fato, a Sociologia das Profissões começou a distinguir-se como disciplina em decorrência dos estudos de Durkheim (1978) acerca da divisão do trabalho social, no qual o autor salienta o papel de associações profissionais reconhecidas tanto pelo Estado quanto pela sociedade, as quais, investidas de poder formal assegurariam a integração e a regulação social.

Parsons (1968), por sua vez, compreendia a identidade de uma profissão como pautada em uma competência técnica e prática, formalmente desenvolvida por instituições educacionais e científicas, dando destaque para os aspectos universais (na aplicação de princípios gerais para solução de problemas específicos de clientes), sociais (relacionados à responsabilidade de suas ações em face da sociedade, ressaltando aqui a questão da 'vocação' profissional) e culturais (principalmente os de cunho coletivista). No entanto as relações entre grupos profissionais e entre eles e estrutura social são aspectos não discutidos por esse autor. Sua preocupação, assim como a de Abott (1988), parece estar mais centrada em explicar o que os 'profissionais' fazem do que como eles se organizam para realizar tais atividades produtivas. Dessa forma, o domínio de um conhecimento assume papel central na abordagem desses dois autores. Por outro lado, as percepções de Parsons (1968) e Abott (1988) permeavam alguns pressupostos, a saber: o processo de profissionalização é unidirecional, um 'caminho sem volta'; a evolução de uma profissão não depende explicitamente do desenvolvimento de outra profissão; os apelos da estrutura social e cultural são mais importantes que o trabalho executado pelas profissões; no interior das profissões prevalece homogeneidade e as diversidades são tidas como contingenciais; e o processo de uma ocupação tornar-se profissão não se altera com o tempo. Tais pressupostos, que desconsideram fatores situacionais e dinâmicos do processo de profissionalização, foram discutidos e combatidos por outros autores, que resistiam à não contextualização das profissões. Convém ressaltar que a expressão 'sistema de profissões' foi cunhada por Abott (1988), através da qual exprimiu sua crença de que profissões entravam em conflito por jurisdição (controle e responsabilidade sobre problemas e soluções pertinentes à profissão), constituindo-se este um ponto central no processo de sua profissionalização.

A profissionalização de determinadas ocupações, Weber (1946) a percebe como processo essencial da modernização no que diz respeito aos estatutos sociais como dependentes das atividades desenvolvidas pelos membros e dos critérios racionais de competência e de especialização. Dubar (1997) aproveita essa discussão para diferenciar 'ofício' - atividade herdada, cujos estatutos são 
atribuídos via socialização prioritariamente comunitária - de 'profissão' - atividade escolhida, cujos estatutos são (re)estruturados via socialização fundamentalmente societária -, apontando para "uma dimensão comunitária estruturante do sistema social global" (Dubar, 1997, p. 127). Assim sendo, as principais categorias da abordagem weberiana seriam o poder, o mercado e o monopólio das profissões enquanto representativas de grupos sociais e, daí, de interesses particulares.

T. J. Johnson (1972), considerado um dos discípulos de Weber sobre o tema, chama a atenção para a variável do poder, sublinhando que uma profissão não é ocupação em si, mas forma de exercer controle sobre ela. Desse modo, um dos aspectos centrais da abordagem desse autor diz respeito aos meios de afiliação que as pessoas (individualmente e em grupo) manipulam com a finalidade de defender interesses particulares, até mesmo no que tange às relações de trabalho, desviando o foco da prestação de serviço, que exige especialização técnica, para necessidades de determinados grupos profissionais. Em decorrência da perspectiva de T. J. Johnson (1972), processos de desprofissionalização e de proletarização de certas profissões são passíveis de análise. Essa linha de pensamento parece visível no trabalho de Child e Fulk (1982), em que os autores sugerem que o controle ocupacional deve ser analisado a partir de quatro fatores: restrição de acesso à base de conhecimento dos profissionais; contexto de emprego profissional; poder e autoridade na relação cliente-profissional; e relacionamentos entre a profissão e as agências ou instituições governamentais.

Outra autora que iniciou seus trabalhos na perspectiva weberiana foi Larson (1977), cuja percepção acerca da ascensão e fortalecimento do profissionalismo retratava explicitamente o surgimento de um novo meio de desigualdade estrutural. Ela entende que as transformações que ocorreram na sociedade mudaram sensivelmente os papéis do mercado e do conhecimento e que ao profissional cabia controlar, com exclusividade, uma expertise superior. Larson (1977) reconhece o processo de profissionalização como algo dinâmico que varia conforme as contingências histórico-culturais, sugerindo a existência de diversos tipos de profissionalismo, com características também diferenciadas. Outra contribuição da autora foi a expressão 'projeto profissional', a qual retrata as estratégias que as lideranças profissionais adotam no sentido de caminharem rumo ao monopólio do mercado de serviços e à mobilidade (ascendente) coletiva, numa ordem social pautada na lógica econômica. Coelho (1999, pp. 51-53) diferencia 'projeto profissional' de 'projeto coletivo', compreendendo que o segundo pode espelhar interesses coletivos, mas não efetivamente de controle da profissão. 
Voltando à especialidade, Starr (1991) trabalha essa questão em consonância com os formatos organizacionais, avançando nas direções relacional e funcional do profissionalismo. Para o autor, a formação e o domínio de uma especialidade é processo permeado por conflitos e, nesse sentido, ele introduz o conceito de 'autoridade cultural' - "construção da realidade através de definições de direitos e valores" (Starr, 1991, p. 28) - diferenciando-o de 'autoridade social' "controle da ação por meio da emissão de ordens" (Starr, 1991, p. 28) -, sendo que a primeira pode residir tanto nos atores sociais, como prescreve a segunda, mas também em objetos culturais e produtos de atividade intelectual passada (Bíblia, dicionários, mapas, trabalhos acadêmicos, leis etc.). A autoridade cultural pode, então, ser usada e consultada sem ser, efetivamente, exercitada ou alterada.

No entanto a perspectiva interacionista de Freidson (1998) traz contribuições de natureza ímpar para a compreensão da formação dessa 'autoridade cultural' . Segundo este autor, o conhecimento tornou-se um poder na sociedade moderna e as profissões constituem-se em suporte de ligação entre os dois, ou seja, interessa a Freidson (1998) a relação entre criação, legitimação, transmissão e aplicação do conhecimento formal e do poder que dele deriva, embebendo, dessa forma, determinadas profissões de um 'poder profissional' no contexto da divisão do trabalho que impera nas organizações. Tal poder advém do monopólio do conhecimento e da autonomia de julgamento do profissional, mesmo em face de normas previamente estabelecidas. Para o autor, uma profissão pode ser considerada como tal se pauta no seguinte elenco: na educação superior e nos conhecimentos formais abstratos que ela repassa; na sua capacidade de exercer poder e de permitir a sobrevivência do sujeito; na tomada da educação como prérequisito seletivo à ocupação de posições e níveis específicos no mercado de trabalho. Todavia Freidson (1998) percebe que, no mundo moderno, se encontra um profissionalismo que

está desprovido das instituições responsáveis pela garantia de meio de vida aos trabalhadores, um profissionalismo expresso puramente como dedicação a um compromisso com a prática de um ofício complexo que tem valor para os outros. Libertá-lo do material interesse próprio é a maneira mais radical pela qual o profissionalismo pode renascer (Freidson, 1998, p. 43).

Agregue-se, aqui, a contribuição de Bourdieu (2003) no sentido de apresentar o sistema de profissões como campo de poder simbólico, ou seja, como elemento 'estruturado' e 'estruturante' que configura, e ao mesmo tempo é configurado, e legitima a relação de dominação pertinente a determinada profissão em certo contexto histórico. 
Dessa maneira, não há como refletir sobre profissões sem considerar as contribuições dos referidos autores, percebendo as complexas relações que envolvem o Estado, as instituições de ensino, as organizações de interesse coletivo e os próprios profissionais.

Nesse ponto, é conveniente esclarecer que, para fins dessa reflexão, se tomará como conceito de profissão o conjunto de atividades produtivas desenvolvidas por um grupo de pessoas que possuem conhecimentos específicos, validados academicamente e reconhecidos socialmente, mediante instrumentos regulatórios formais ou informais que são compartilhados coletivamente, garantindo elevado grau de autonomia no exercício de suas atribuições, movidas em certo nível por altruísmo ${ }^{(9)}$.

Percebe-se, portanto, como fecundo o campo das profissões e seu embate com o conceito e a gestão de competências, possibilitando traçar algumas perspectivas de pesquisa.

\section{Perspectivas de Pesquisas}

\section{Aspectos Metodológicos}

Do ponto de vista metodológico, pesquisas descritivo-comparativas com profissionais que trabalhem com organizações ou em organizações de um mesmo setor de atividade podem permitir a identificação, compreensão e comparação de aspectos individuais e de gestão, presentes em tais locais de trabalho, no que tange à formação e desenvolvimento de competências profissionais. $\mathrm{O}$ enfoque de pesquisas que conecta os referidos temas pode ser, num primeiro momento, essencialmente qualitativo tendo em vista dois aspectos fundamentais: conceitual, pela busca da compreensão dos significados e das relações subjacentes a situações e fatos descritos pelos profissionais (Cozby, 2003; Richardson, 1999; Triviños, 1987); e pragmático, pois os processos de profissionalização e, também, os relacionados à gestão de competências seguem percursos, estágios e ciclos muitas vezes diferentes (Carvalho \& Azevedo, 2004; Coelho, 1999), carecendo de tratamento particular e individualizado.

Em termos de instrumentos de coleta de dados, poderão ser utilizados: pesquisa documental (focando em dados legais e normativos, provenientes de entidades de interesse coletivo, associações de classe, sindicatos, conselhos profissionais, das próprias organizações etc.), entrevistas não estruturadas ou semi-estruturadas e observação direta, conforme tipificação de Bruyne, Herman e Schoutheete 
(1977). Conjugadas às entrevistas, as técnicas projetivas de associação parecem ser frutíferas fontes de dados em pesquisas dessa natureza: Bailey (1982) e Bryman (1992) argumentam que elas envolvem a apresentação de um estímulo ambíguo para os indivíduos, cuja interpretação é tomada pelo pesquisador para revelar algumas características fundamentais da preocupação individual. Segundo Loizos (2002), as imagens constituem ricas fontes de dados, tendo em vista que a comunicação de entrevistador e entrevistado é mais ampla do que a 'oralidade' permite, concretizando-se tal técnica projetiva em profícua fonte de dados. Selltiz, Jahoda, Deutsch e Coo (1965, p. 320) concordam nesse sentido, afirmando que "ilustrações são valiosas na descrição de muitos tipos de situações difíceis de descrição; assim, elas permitem a manifestação de reações que de outro modo são difíceis de obtenção". Outras opções no mesmo sentido seriam os testes projetivos adaptados, como os aplicados por Melo (1991); e as técnicas projetivas de construção, como as gráficas ou de desenho, conforme Kolck (1984) e Zuboff (1988), e as de história oral temática, de acordo com Meihy (2002) e Thompson (1992). O objetivo da aplicação dessas técnicas seria tentar captar percepções e concepções que não foram ditas ou contempladas na entrevista ou no discurso 'formal' do entrevistado. O uso do grupo focal e de indicações subseqüentes de entrevistados pelos próprios integrantes do grupo pesquisado são técnicas complementares de coleta de dados que permitem ir além do conhecimento conceitual e prático do pesquisador.

No que tange ao tratamento dos dados, aqueles provenientes de fontes secundárias deverão ser submetidos à análise documental (Bardin, 1977; Fiorin, 1989; Orlandi, 2001). Já aos dados primários sugere-se tratamento e análise em três etapas: preparação, tabulação quantitativa e tabulação qualitativa. A preparação constituir-se-á de:

a) transcrição na íntegra das gravações, permitindo a apreensão de lapsos verbais, frases indicativas de contradições, repetições de frases etc., bem como a inclusão de observações (expressões corporais, por exemplo) percebidas no momento de realização da entrevista;

b) releitura dos dados e sua organização preliminar em torno do roteiro de entrevista e aspectos relevantes colocados pelos entrevistados.

As duas outras etapas se sujeitarão aos critérios de repetição e de relevância (Bardin, 1977; Melo, 2003; Turato, 2003) que dizem, respectivamente, de destacar reincidências nos relatos e a essência do fenômeno observado. Conforme descreve Melo (1991, pp. 20-21), a tabulação quantitativa se dá a partir da "identificação de componentes das respostas dos entrevistados, permitindo o agrupamento de dados, a recuperação de conhecimento relativo a determinadas questões e a construção de tabelas", pautando-se, portanto, na estatística 
descritiva e, frise-se, apresentada posteriormente no formato de tabelas, de maneira a se obter visão mais ampla, quantificada e resumida das entrevistas. Já a tabulação qualitativa, ou análise temática, ou ainda categorização temática, é descrita pela autora como a "definição de temas e agrupamento dos estratos mais significativos, retirados das entrevistas, dando destaque à dimensão do dito ou da fala do entrevistado", permitindo a construção de uma planilha de análise que considerará tanto "a vivência do sujeito, a partir do seu discurso, como ponto de partida para aplicação de teorias explicativas, mas de considerálo também como objeto teórico, e de estudar simultaneamente os diversos componentes de referência dessa experiência dos entrevistados" (Melo, 1991, p. 21). Assim, a partir de releituras de todas as entrevistas e da extração de temas e idéias que, a princípio, não foram enfatizados no roteiro, mas se manifestaram como alvo de preocupação dos entrevistados, essa metodologia permite ir além do próprio conhecimento e, mais uma vez, considerar o saber e a vivência do entrevistado.

Para tanto, na análise de dados, sugerem-se técnicas de análise de conteúdo e de discurso, comumente usadas em pesquisas dessa natureza. A primeira é concebida por Bardin (1977) como um aglomerado de técnicas de análise das comunicações, o qual engloba procedimentos sistemáticos e objetivos de descrição do conteúdo das mensagens, incluindo-se aqui estruturas psicológicas e sociológicas, com a finalidade de mostrar tanto o que foi dito explicitamente, como desnudar as condutas, ideologias e atitudes que o invadem. Isto se dá por meio de indicadores (quantitativos ou não) que permitem inferir conhecimentos relativos às condições de produção e recepção (varáveis inferidas) dessas mensagens. Já na análise de discurso, segundo Alvesson e Skölberg (2000), o foco não está na linguagem como uma entidade abstrata, como o léxico ou um conjunto de regras gramaticais. Ela caracteriza-se como meio de interação e enfatiza o modo como as versões de mundo, de sociedade, de eventos e de mundos psicológicos interiores são produzidos no discurso. Orlandi (2001) vê nessa técnica de análise de dados a possibilidade e o objetivo de compreender o significado que a linguagem tem para o sujeito e, portanto, inseparável da sociedade que o produz.

Com intuito de integrar os conceitos relacionados à competência profissional, gestão de competências e profissionalismo, apresenta-se um modelo teóricoconceitual inicialmente adotável em pesquisas dessa natureza, no qual se pode visualizar atores sociais, aspectos relevantes de sua atuação no campo das competências e do profissionalismo, relações entre eles e contextos que os permeiam. Esse modelo proposto pode ser visualizado na Figura 1. 
Figura 1: Modelo Teórico-conceitual Proposto para Pesquisa

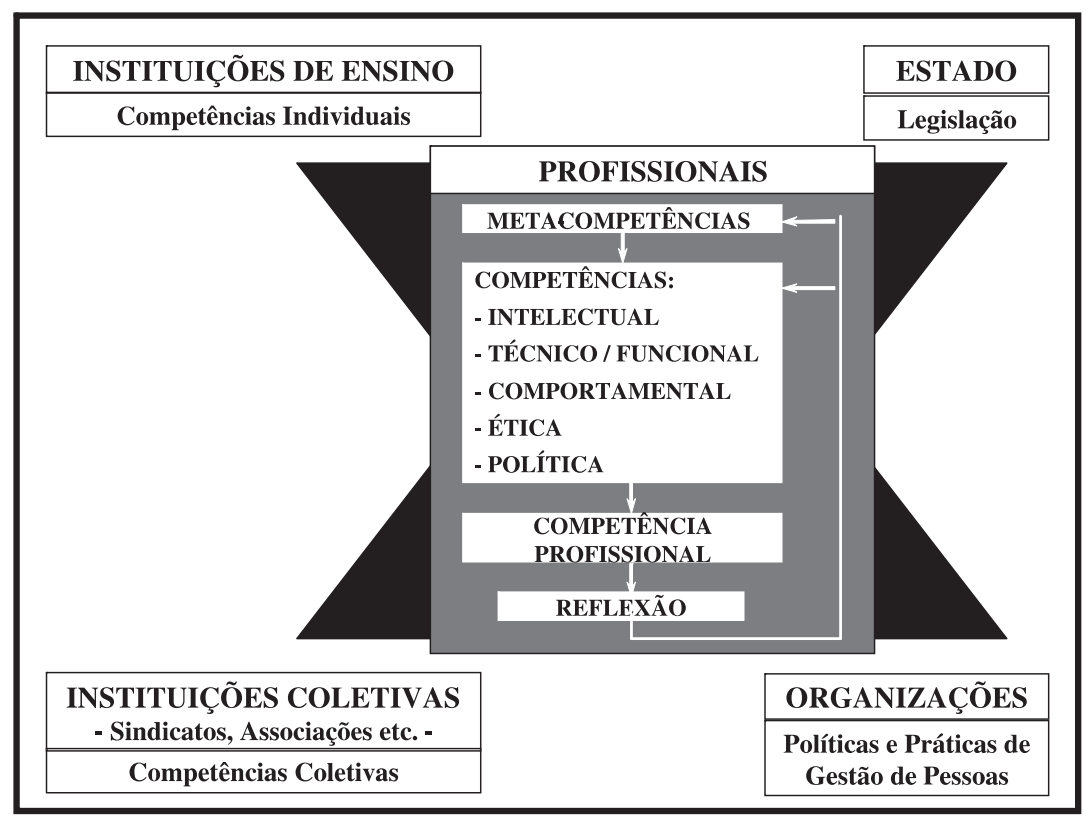

Fonte: Levantamento bibliográfico.

Após privilegiar as abordagens qualitativas, os procedimentos quantitativos e modelos matemáticos explicativos parecem ser apropriados na proposição e confirmação de variáveis e premissas identificadas e passíveis de extensão a populações ou universos profissionais mais abrangentes. Dessa maneira, a validação de modelos e escalas através de questionários parece ser o passo subseqüente em pesquisas da natureza aqui proposta.

Cabe ressaltar, neste ponto, a contribuição de Demo (2002), autor que sublinha que o objetivo da pesquisa qualitativa é desnudar os aspectos menos formais dos fenômenos em estudo, sem desconsiderar, no entanto, sua faceta quantitativa, já que tal dicotomia não é, segundo ele, real. Para Demo (2002), todo fenômeno histórico quantitativo que envolve o ser humano contém uma dimensão qualitativa; o qualitativo, por sua vez, é histórico e guarda, dessa forma, um contexto material e espaciotemporal. $\mathrm{O}$ autor conclui que dicotomização absoluta entre tais faces é apenas uma ficção conceitual.

\section{Aspectos Temáticos}

Em termos de perspectivas temáticas de pesquisas que abracem os construtos competência profissional, gestão de competências e profissões, percebem-se algumas possibilidades: 
. Em profissões com vínculos de trabalho diferenciados, como é o caso dos médicos, considerando-se a formação e o crescimento das clínicas e das cooperativas de saúde e de trabalho, as quais têm agregado grande número de profissionais e viabilizado a prestação de serviço e o relacionamento com clientes, atentando, por outro lado, às relações que se travam com outras categorias profissionais, como enfermeiros, farmacêuticos, terapeutas, nutricionistas etc., que afetam o resultado final dos serviços que os médicos prestam a seus pacientes.

- Atentando para suas variações no interior da profissão, como no caso de administradores (em níveis hierárquicos diferenciados, em áreas distintas, em setores em ascensão - como turismo, hotelaria, hospitalar, educação, cooperativas etc.), publicitários (áreas de planejamento, mídia, atendimento, criação etc.), engenheiros (engenharia civil, mecânica, elétrica, eletrônica, de produção etc.) e policiais (militares e civis, principalmente em face das possibilidades de aglutinação de ambos num só grupo), e para os vínculos com conselhos profissionais, com instituições de ensino e com políticas econômicas.

. Entre profissionais da iniciativa privada e do setor público, como no caso da advocacia, enfatizando variações no interior da profissão (direito civil, penal, criminal, processual, administrativo, internacional etc.), no seio dos escritórios, das organizações, de tribunais (juízes, promotores), no relacionamento com recém-formados e estagiários.

. Em partes de categorias profissionais pouco investigadas. Neste caso se encaixam, por exemplo, docentes de ensino superior, podendo-se enfatizar as proposições da Lei de Diretrizes e Bases da Educação Nacional (1996), que afetam o quadro de pessoal e as próprias instituições de ensino, enquanto formadoras e também como meios de absorção desses profissionais e, daí, os movimentos de associações de professores, sindicatos etc.

. Em termos das políticas e práticas de gestão de pessoas empreendidas por organizações, nas quais ou com as quais os profissionais trabalham, atentando para tipo de vínculo, ou seja, como empregados, como cooperados (organizações cooperativas), como voluntários (organizações sem fins lucrativos ou do terceiro setor) etc.

- Acerca das relações entre profissionais e seus respectivos conselhos, de um ponto de vista mais institucional, com vistas a mapear seu grau de representatividade, sua colaboração com a formação e o desenvolvimento das competências individuais e coletivas, seus mecanismos formais e informais de fazerem face às 'leis de mercado'. 
. Entre os grupos de profissionais, quer numa mesma profissão, quer em profissões diferenciadas, em perspectiva mais fenomenológica, com vistas a compreender como se articulam, individual, coletiva e socialmente, como se representam coletivamente, como se percebem na sociedade e sob a égide das 'leis de mercado'; como se relacionam com suas competências profissionais etc.

. Correlacionando com outros construtos: estresse ocupacional (como categorias de análise relacionadas ao profissionalismo e à gestão de competências colaboram com o estresse, reduzindo-o ou alimentando-o), identidade (nas diversas perspectivas de análise - pessoal, social, no trabalho e organizacional, conforme Machado (2003), e institucional, de acordo com Lawn (2000), colaborando na construção de uma 'identidade profissional' mais fraca ou forte), função gerencial (nas relações de poder desenvolvidas no interior das organizações, mediante um profissionalismo mais, ou menos, avançado e/ou uma gestão de competências mais 'arcaica' / 'moderna' etc.), ação administrativa (sob a ótica de vertentes estruturalistas, nos níveis individuais, profissionais, grupais e organizacionais).

\section{CONSIDERAÇÕES}

Os objetivos deste ensaio foram dois: refletir sobre os conceitos de competência profissional, gestão de competências e profissão; e indicar possibilidades de pesquisas, tanto em termos metodológicos como temáticos.

Para tanto este trabalho apoiou-se em autores e perspectivas da Administração (Teorias das Organizações, Gestão de Competências), da Educação (Competências Profissionais), da Sociologia (Sociologia das Profissões), com vistas a introduzir outras perspectivas de análise e, com isso, colaborar com a delimitação dos construtos envolvidos, principalmente acerca da competência profissional e de sua gestão e, ao mesmo tempo, ampliar e aprofundar seu entendimento, a partir de percepções diferentes e detalhadas de outros processos que as permeiam, como é o caso da profissionalização.

No que diz respeito à 'competência profissional', concorda-se com Le Boterf (2003): trata-se de conceito em construção, interdisciplinar e diferenciado de 'qualificação'. Ao final da discussão, a proposta conceitual para competência profissional refere-se à mobilização de forma particular pelo profissional na sua ação produtiva de um conjunto de saberes de naturezas diferenciadas (que formam as competências intelectual, técnico-funcionais, comportamentais, éticas e políticas) de maneira a gerar resultados reconhecidos individual (pessoal), coletiva 
(profissional), econômica (organização) e socialmente (sociedade). Tal conceito resgata a percepção do caráter social da construção e da manutenção da competência profissional (Dubar, 1997), negando uma formação pontual, estática ou descolada da realidade prática e da reflexão conceitual.

Já a 'gestão de competências' foi percebida como componente fundamental da gestão de pessoas no interior das organizações, porém a ela transcende, no sentido que características individuais, como personalidade e motivação, influem decisivamente nesses processos e implicam uma diversidade complexa e de difícil gerenciamento nas esferas tanto institucional, como coletiva e individual. Daí optou-se pela utilização da terminologia 'gestão de competências' de maneira a sintetizar tanto os esforços organizacionais, mais conhecidos como 'gestão por competências', como os individuais, coletivos e sociais. Porém, nas bibliografias visitadas, as atividades relacionadas às políticas e práticas de gestão de pessoas conjugadas sob a égide da competência profissional mais se referem à qualificação do que efetivamente à competência. Concorda-se com Ramos (2001), quando a autora reforça a necessidade de construção de um sistema profissional pautado em competências que concilie, de maneira estratégica, projetos individuais, institucionais e sociais. A conexão entre profissionais, organizações, educação e governo implicaria, inevitavelmente, o redimensionamento do processo de profissionalização, chamando à reflexão a questão da 'profissão'.

Após a leitura dos clássicos da Sociologia das Profissões, percebeu-se que os adjetivos 'liberal' ou 'livre' não cabem no sistema produtivo brasileiro e propôsse o seguinte conceito de profissão: conjunto de atividades produtivas desenvolvidas por um grupo de pessoas que possuem conhecimentos específicos, validados academicamente e reconhecidos socialmente, mediante instrumentos regulatórios formais ou informais que são compartilhados coletivamente, garantindo elevado grau de autonomia no exercício de suas atribuições, movidas em certo nível por altruísmo.

Ressalte-se que, em relação aos indivíduos, é substancial para sua manutenção no mercado de trabalho (independentemente de vínculo empregatício) refletir sobre suas competências, nos modos como as organizações estruturam suas políticas e práticas de gestão, na conformação de sua profissão nos níveis micro, meso e macroambientais, e no seu posicionamento particular em face de tudo isso. Aos grupos, normalmente unidos por área de trabalho e por nível hierárquico, instiga-se uma reflexão no âmbito da profissão, com vistas à manutenção dos processos de identificação e diferenciação, que tomam contornos diferenciados, quando analisados na ótica apresentada neste estudo. No que diz respeito às organizações, um gerenciamento efetivo das pessoas contempla diretamente suas competências, fato que, muitas vezes, tem sido traduzido por práticas centradas 
em qualificações que alimentam diversos processos pessoais e grupais, que podem estar alinhados, ou não, com a efetividade organizacional.

Nesses termos, foram apontadas algumas possibilidades de pesquisa, abrangendo tanto aspectos metodológicos como temáticos. Quanto aos primeiros, propôs-se inicialmente abordagens mais qualitativas que permitissem dar profundidade à compreensão dos temas envolvidos e das suas relações inerentes; num segundo momento, abordagens mais quantitativas parecem ser frutíferas na validação de modelos e escalas. Em termos temáticos, apresentou-se um leque de opções, que contemplava profissões que se encontram em momentos diferenciados no que diz respeito a processo de profissionalização, buscando compreender aspectos tanto particulares, como extensivos a outras demais.

Os intuitos da proposição de uma agenda de pesquisa foram de colaborar em dois sentidos: primeiro, conceitual e academicamente, em termos de precisar e, ao mesmo tempo, expandir a delimitação dos construtos envolvidos; e, segundo, prática e profissionalmente, no que tange a fornecer subsídios para nova postura dos atores sociais envolvidos nos processos de profissionalização a que se tem assistido e presenciado.

Convém ressaltar que não houve a pretensão de restringir ou exaurir a discussão em torno das temáticas aqui tratadas, mas dar contribuições acerca de processos complexos, permeados de interesses diversificados, como é o caso da gestão de competências e da profissionalização.

\section{Artigo recebido em 21.07.2005. Aprovado em 27.10.2005.}

\section{NOTAS}

${ }^{1}$ Villa (1998, p. 30) entende o termo "figura" como "uma unidade que expressa mais que a soma das partes, baseada mais na marca que foi criando a imagem mitológica do professor, na impressão de sua missão".

${ }^{2}$ Conforme evidenciado por Silva, L. M. (2002). Qualificação versus competência: um comentário bibliográfico sobre um debate francês recente. Revista Brasileira de Informações Bibliográficas em Ciências Sociais, 1(53), 103-117.

${ }^{3}$ Autores como McClelland, D. C., \& Dailey, C. (1972). Improving officer selection for the foreign service. Boston: McBer. e Boyatzis, R. E. (1982). The competent manager. New York: Wiley.

${ }^{4}$ Le Boterf, G. (1999). Competénce et navigation professionnelle. Paris: Les Editions D'organisation, Zarifian, P. (1996). A gestão da e pela competência [Mimeo]. Centro Internacional para a Educação, Trabalho e Transferência de Tecnologia, Seminário Educação Profissional, Trabalho e Competências, Rio de Janeiro, RJ. e Jacques, E. (1990). In praise of hierarchy. Harvard Business Review, 68(1), 127-133, são alguns dos autores mais conhecidos dessa linha. 
${ }^{5}$ Os termos "reflexão-na-ação" e "reflexão-sobre-a-ação" são utilizados pelos autores nos moldes propostos por Schön, D. A. (1983). The reflective practitioner. London: Maurice Temple Smith, Schön, D. A. (1987). Educating the reflective practitioner. San Francisco, CA: Jossey-Bass, em termos do "conhecimento na ação", "reflexão na ação" e "reflexão sobre a ação e sobre a reflexão na ação", denotando desenvolvimento do pensamento prático num processo circular constante.

${ }^{6}$ Essa perspectiva vai ao encontro à de Demo (2002, p. 213), autor que sublinha que "o aprender a aprender indica uma visão didática composta de dois horizontes entrelaçados, pervadidos pela competência fundamental do ser humano, que é a competência de construir a competência, em contato com o mundo, com a sociedade, num processo interativo produtivo".

${ }^{7}$ Sobre competitividade, Levy-Leboyer, C. (1997). Gestión de las competencias. Barcelona: Gestión 2000, sublinha que um de seus sustentáculos é configurado por políticas de gestão de pessoas atenta ao desenvolvimento dos indivíduos.

${ }^{8}$ Como Gramigna, M. R. (2002). Modelo de competências e gestão dos talentos. São Paulo: Makron Books, Quinn, R. E., Faerman, S. R., Thompson, M. P., \& McGrath, M. R. (2003). Competências gerenciais. Rio de Janeiro: Elsevier, e Daólio, L. C. (2004). Perfis \& competências. São Paulo: Érica, dentre outros.

${ }^{9} \mathrm{O}$ conceito proposto inclui as chamadas semiprofissões, terminologia cunhada por Etzioni, A. (Org.). (1969). The semi-professions and their organization. New York: The Free Press, em virtude de algumas ocupações estarem submetidas à autoridades formais intra-organizacionais, apesar de buscarem autonomia no processo de trabalho, reconhecimento, status e poder. Essa distinção não parece importante no contexto atual pelos mesmos motivos que não cabem mais as terminologias "profissão liberal" ou "profissão livre", conforme Villa (1998) e Carvalho e Azevedo (2004).

\section{RefERÊNCIAS Bibliográficas}

Abott, A. (1988).

The system of professions. Chicago:

The University of Chicago Press.

Alvesson, M., \&

Sköldberg, K. (2000).

Reflexive methodology. London:

Thousand Oaks, New Delhi: Sage.

Bailey, K. D. (1982).

Methods of social research. New York:

The Free Press.

Barbosa, M. L. (2003).

O ensaio bibliográfico - as profissões no Brasil e sua sociologia. Dados, 46(3), 593-607.
Bardin, L. (1977).

Análise de conteúdo. Lisboa: Edições 70.

Bitencourt, C., \&

Barbosa, A. C. Q. (2004).

A gestão de competências. In $\mathrm{C}$. Bitencourt (Org.). Contemporânea de pessoas. Porto Alegre: Bookman.

Bonelli, M. G., \&

Donatoni, S. (1996).

Os estudos sobre profissões nas ciências sociais brasileiras. Revista Brasileira de Informações Bibliográficas em Ciências Sociais, 1(41), 109-142. 
Boudon, R., \&

Bourricaud, F. (1993).

Dicionário crítico de sociologia. São Paulo: Ática.

Bourdieu, P. (2003).

$O$ poder simbólico (6a ed.). Rio de Janeiro: Bertrand Brasil.

Brandão, H. P., \&

Guimarães, T. A. (2001).

Gestão de competências ou gestão de desempenho: tecnologias distintas ou instrumentos de um mesmo construto. Revista de Administração de Empresas, 41(1), 8-15.

Brígido, R. V. (1999).

Criação de uma rede nacional de certificação de competências nacionais. In Organização Internacional do Trabalho. Certificação de competências profissionais: discussões. Brasília: OIT, MTE/FAT.

Bruyne, P.,

Herman, J., \&

Schoutheete, M. (1977).

Dinâmica da pesquisa em ciências sociais. Rio de Janeiro: Francisco Alves.

Bryman, A. (1992).

Research methods and organization studies. London: Unwin Hyman.

Carvalho, L. M. G. X., \&

Azevedo, C. A. S. (2004).

Breve história das profissões liberais no Brasil. Revista das Profissões Liberais, (Edição Especial). Recuperado em 12 abril, 2005, de http://www.cnpl.org.br/ revista/revista_especial.pdf
Cheetham, G., \&

Chivers, G. (1996).

Towards a holistic model of professional competence. Journal of European Industrial Training, 20(5), 20-30.

Cheetham, G., \&

Chivers, G. (1998).

The reflective (and competent) practitioner. Journal of European Industrial Training, 22(7), 267-276.

Cheetham, G., \&

Chivers, G. (2000).

A new look at competent professional practice. Journal of European Industrial Training, 24(7), 374-383.

Child, J., \&

Fulk, J. (1982).

Maintenance of occupational control: the case of professions. Work \& Occupations, 9(2), 155-192.

Coelho, E. C. (1999).

As profissões imperiais. Rio de Janeiro: Record.

Cozby, P. C. (2003).

Métodos de pesquisa em ciências do comportamento. São Paulo: Atlas.

Dadoy, M. (2004).

As noções de competência e competências à luz das transformações na gestão da mão-de-obra. In A. Tomasi (Org.). Da qualificação à competência. Campinas: Papirus.

Demailly, L. (1987).

La qualification ou la compétence professionnelle des enseignants. Sociologie du Travail, 29(1), 59-69. 
Demo, P. (2002).

Desafios modernos da educação. Petrópolis, RJ: Vozes.

Desaulniers, J. B. R. (1997).

Formação, competência e cidadania. Educação \& Sociedade, 18(60), 5163.

Dubar, C. (1997).

A socialização. Portugal: Porto Editora.

Dugué, E. (2004).

A lógica da competência: o retorno do passado. In A. Tomasi (Org.). Da qualificação à competência. Campinas: Papirus.

Durkheim, E. (1978).

Da divisão do trabalho social. São Paulo: Abril.

Dutra, J. S. (2004).

Competências. São Paulo: Atlas.

Dutra, J. S.,

Hipólito, J. M., \&

Silva, C. M. (1998).

Gestão de pessoas por competências. Anais do Encontro Nacional da Associação Nacional de PósGraduação e Pesquisa em Administração, Foz do Iguaçu, PR, Brasil, 22.

Elias, N. (1987).

Profissões. In B. Silva (Coord.). Dicionário de ciências sociais. Rio de Janeiro: Fundação Getúlio Vargas.

Fiorin, J. L. (1989).

Elementos de análise do discurso. São Paulo: Contexto.
Fleury, A., \&

Fleury, M. T. L. (2001).

Estratégias empresariais e formação de competências. São Paulo: Atlas.

Freidson, E. (1998).

Renascimento do profissionalismo. São Paulo: EDUSP.

Gyarmati, K. G. (1975).

Professions: an ideology? International Social Science Journal, 27(4), 673-699.

Heijden, B., \&

Barbier, G. (2004).

A competência, sua natureza e seu desenvolvimento: uma abordagem anglo-saxônica. In A. Tomasi (Org.). Da qualificação à competência. Campinas: Papirus.

Johnson, A. G. (1997).

Profissão liberal e profissionalização. In A. G. Johnson. Dicionário de sociologia: guia prático da linguagem sociológica. Rio de Janeiro: Jorge Zahar.

Johnson, T. J. (1972).

Professions and power. London: MacMillan.

Larson, M. S. (1977).

The rise of professionalism. Berkeley, Ca: University of California Press.

Lawn, M. (2000).

Os professores e a fabricação de identidades. In A. Nóvoa \& J. A. Schriewer (Orgs.). Difusão Mundial da Escola. Lisboa: Educa.

Le Boterf, G. (2003).

Desenvolvendo a competência dos profissionais. Porto Alegre: Artmed Editora. 
Lewis, M. W., \&

Grimes, A. J. (2005).

Metatriangulação: a construção de teorias a partir de múltiplos paradigmas. Revista de Administração de Empresas, 45(1), 72-91.

Lima, M.E. A. (1995).

Os equívocos da excelência. Petrópolis: Vozes.

Loizos, P. (2002).

Vídeo, filme e fotografias como documentos de pesquisa. In M. W. Bauer \& G. Gaskell (Orgs.). Pesquisa qualitativa com texto, imagem e som - um manual prático. Petrópolis: Vozes.

Machado, H. V. (2003).

A identidade e o contexto organizacional: perspectivas de análise. Revista de Administração Contemporânea, 7(Edição Especial), 51-73.

Manfredi, S. M. (1999).

As metamorfoses da qualificação: três décadas de um conceito. Anais do Encontro Anual da Associação Nacional de Pós-Graduação e Pesquisa em Ciências Sociais, Caxambu, MG, Brasil, 23.

McLagan, P. A. (1997)

Competencies: the next generation. Training and Development, 51(5), 4047.

Meihy, J. C. S. B. (2002). Manual de história oral. São Paulo: Loyola.

Melo, M. C. O. L. (1991). Estratégia do trabalhador informático nas relações de trabalho. Tese de Professor Titular. Facul- dade de Ciências Econômicas, Universidade Federal de Minas Gerais, Belo Horizonte, MG, Brasil.

Melo, M. C. O. L. (2003, dezembro).

A gerência feminina em setores industrial e bancário: o conservadorismo internalizado versus o moderno em construção. Proceedings of the International Conference of the Iberoamerican Academy of Management, São Paulo, SP, Brasil, 3.

Orlandi, E. P. (2001). Análise de discurso. Campinas: Pontes.

Pages, M., Bonetti, M.,

Gaulesiac, M., \&

Descendre, T. (1987).

O poder das organizações. São Paulo: Atlas.

Parsons, T. (1968).

Professions. In D. L. Sills (Org.). International Encyclopedia of the Social Sciences (Vol. 12). New York: The Macmillan Company \& The Free.

Perrenoud, P. (1999).

Construir as competências desde a escola. Porto Alegre: Artmed Editora.

Ramos, M. N. (2001).

A pedagogia das competências. São Paulo: Cortez.

Richardson, R. J. (Org.). (1999).

Pesquisa social: métodos e técnicas. São Paulo: Atlas.

Roche, J. (2004).

A dialética qualificação - competência: estado da questão. In A. Tomasi (Org.). Da qualificação à competência. Campinas: Papirus. 
Roos, P. A. (2000).

Professions. In E. F. Borgatta \& R. J. V. Montgomery (Eds.). Encyclopedia of Sociology. New York: Macmillan Reference.

Ropé, F., \&

Tanguy, L. (1997).

Introdução. In F. Ropé \& L. Tanguy (Orgs.). Saberes e competências: o uso de tais noções na escola e na empresa. Campinas: Papirus.

Ruas, R. L. (2001).

Desenvolvimento de competências gerenciais e contribuição da aprendizagem organizacional. In M. T. L. Fleury \& M. M. Oliveira Jr. (Orgs.). Gestão estratégica do conhecimento. São Paulo: Atlas.

Ruas, R. L. (2005).

Gestão por competências: uma contribuição à estratégia das organizações. In R. L. Ruas, C. S. Antonello, \& L. H. Boff (Orgs.). Os novos horizontes da gestão: aprendizagem organizacional e competências. Porto Alegre: Bookman.

Selltiz, C.,

Jahoda, M.,

Deutsch, M., \&

Coo, S. M. (1965).

Métodos de pesquisa das relações sociais. São Paulo: Herder.

Sparrow, P. R., \&

Bognanno, M. (1994).

Competency requirement forecasting: issues for international selection and assessment. In C. Mabey \& P. Iles
(Orgs.). Managing Learning (pp. 5769). London: Routledge.

Starr, P. (1991).

La transformación social de la medicina en los Estados Unidos de América. México: Fondo de Cultura Econômica.

Scitovisky, T. (1966).

An international comparison of the trend of professional earnings. American Economic Review, 56(1), 25-42.

Thompson, P. (1992).

A voz do passado; história oral. Rio de Janeiro: Paz e Terra.

Tomasi, A. (2004a).

Qualificação ou competência? In A. Tomasi (Org.). Da qualificação à competência. Campinas: Papirus.

Tomasi, A. (Org.). (2004b).

Da qualificação à competência. Campinas: Papirus.

Triviños, A. N. S. (1987).

Introdução à pesquisa em ciências sociais. São Paulo: Atlas.

Turato, E. R. (2003).

Tratado de metodologia da pesquisa clínico-qualitativa: construção teórico-epistemológica, discussão comparada e aplicação nas áreas de saúde e humanas. Petrópolis: Vozes.

Kolck, O. L. van (1984).

Testes projetivos gráficos no diagnóstico psicológico. São Paulo: EPU. 
Veiga, I. P. A. (1998).

Avanços e equívocos na profissionalização do magistério e a nova LDB. In I. P. A. Veiga (Org.). Caminhos da profissionalização do magistério. Campinas: Papirus.

Villa, F. G. (1998).

O professor em face das mudanças culturais e sociais. In I. P. A. Veiga (Org.). Caminhos da profissionalização do magistério. Campinas: Papirus.

Waddington, I. (1996).

Professions. In A. Kuper \& J. Kuper (Eds.). The social science encyclopedia. London, New York: Routledge.
Weber, M. (1946).

Ensaios de sociologia. Rio de Janeiro:

Zahar.

Woodruffe, C. (1991).

Competent by any other name. Personnel Management, 23(9) 30-33.

Zarifian, P. (2001).

Objetivo competência: por uma nova lógica. São Paulo: Atlas.

Zuboff, S. (1988).

In the age smart machine-the future of work and power. USA: Basic. 